\title{
Transtorno do espectro autista (TEA) e os processos de reconhecimento em contextos educacionais: relações de poder e resistência
}

\author{
Autistic spectrum disorder (ASD) and recognition processes in \\ educational contexts: relations of power and resistance
}

Trastorno del espectro autista (TEA) y procesos de reconocimiento en contextos educativos: relaciones de poder y resistencia

Marco Antonio Torres ${ }^{1}$; Ana Carolina Alves Silva ${ }^{2}$; Vanessa da Silva Estevam ${ }^{3}$

\section{RESUMO}

O presente artigo analisou os desafios do desenvolvimento psicossocial no contexto da educação básica, a partir de discursos acerca de crianças com Transtorno do Espectro Autista (TEA). Como metodologia de pesquisa, elegeu-se o levantamento bibliográfico, bem como a entrevista narrativa com uma mãe de duas crianças diagnosticadas com a Síndrome de Asperger, que entendemos dentro do TEA. Utilizamos a noção de reconhecimento a partir de Butler (2015) para dialogar com os objetivos da pesquisa. Os resultados indicaram como os processos de reconhecimento das pessoas com deficiência no contexto escolar ainda são insuficientes, por isso exigem formas de resistências aos discursos de assujeitamento destas pessoas. As investigações também indicaram a importância de cooperação entre familiares e profissionais da educação para o reconhecimento das pessoas com deficiência. Por fim, as análises destacaram a luta de uma mãe, mobilizada pela razão e pelos afetos, nas relações de poder e resistência no contexto de uma educação inclusiva ainda insuficiente.

Palavras-chave: Desenvolvimento Psicossocial; Reconhecimento; Síndrome de Asperger.

\begin{abstract}
This article analyzed the challenges of psychosocial development in the context of basic education, based on speeches about children with ASD. As a research methodology, the bibliographic survey was chosen, as well as the narrative interview with a mother of two children diagnosed with Asperger's Syndrome. We used the notion of recognition from Butler (2015) to dialogue with the research objectives. The results indicated how the processes of recognition of people with disabilities in the school context are still insufficient, which is why they require forms of resistance to the discourse of subjection of these people. The investigations also indicated the importance of cooperation between family members and education professionals for the recognition of people with disabilities. Finally, the analyzes highlighted the struggle of a mother, mobilized by reason and affections, in the relations of power and resistance in the context of an insufficient inclusive education.
\end{abstract}

Keywords: Psychosocial Development; Recognition, Asperger Syndrome.

\footnotetext{
${ }^{1}$ Possui graduação, mestrado e doutorado em Psicologia. É professor permanente do Programa de PósGraduação em Educação da Universidade Federal de Ouro Preto (UFOP), Ouro Preto/MG - Brasil. E-mail: torresgerais@gmail.com

${ }^{2}$ Graduada em Pedagogia e Mestra em Educação na Universidade Federal de Ouro Preto (UFOP), Ouro Preto/MG - Brasil. E-mail: alves7anacarolina@gmail.com

${ }^{3}$ Graduanda do curso de Licenciatura em Pedagogia na da Universidade Federal de Ouro Preto (UFOP), Ouro Preto/MG - Brasil. E-mail: vanessa.estevam@aluno.ufop.edu.br
} 


\section{RESUMEN}

Este artículo analiza los desafíos del desarrollo psicosocial en el contexto de la educación básica, a partir de discursos sobre niños con TEA. Como metodología de investigación se eligió la encuesta bibliográfica, así como la entrevista narrativa con una madre de dos niños diagnosticados con síndrome de Asperger. Utilizamos la noción de reconocimiento de Butler (2015) para dialogar con los objetivos de la investigación. Los resultados indicaron cómo los procesos de reconocimiento de las personas con discapacidad en el contexto escolar son aún insuficientes, por lo que requieren formas de resistencia al discurso de sujeción de estas personas. Las investigaciones también señalaron la importancia de la cooperación entre familiares y profesionales de la educación para el reconocimiento de las personas con discapacidad. Finalmente, los análisis destacaron la lucha de una madre, movilizada por la razón y los afectos, en las relaciones de poder y resistencia en el contexto de una insuficiente educación inclusiva.

Palabras clave: Desarrollo Psicosocial; Reconocimiento, Síndrome de Asperger.

\section{INTRODUÇÃO}

O objetivo da pesquisa apresentada nesse artigo foi analisar os desafios do desenvolvimento psicossocial e a produção do reconhecimento de crianças com TEA (Transtorno do Espectro Autista) na educação básica, no contexto da educação inclusiva. Inicialmente foi realizado um levantamento bibliográfico em que situamos nossa localização no debate. Também realizamos uma entrevista narrativa com Rosa (pseudônimo), mãe de duas crianças em idade escolar diagnosticadas com Síndrome de Asperger, está localizada dentro do TEA. A pesquisa se orienta por uma perspectiva teórico-metodológica pós estruturalistas que compreende os processos de subjetivação a partir dos discursos e suas articulações.

Localizamos uma articulação do conceito de espectro autista proposto na pesquisa de Lorna Wing e Judith Gould (1979), porém os estudos sobre o autismo remontam a primeira metade do século XX. Rivière (2004) faz um percurso histórico desde as pesquisas de Leo Kanner e Hans Asperger, na década de 1940, quando propuseram o diagnóstico do autismo, até posições do Manual Diagnóstico e Estatístico de Transtornos Mentais, o DSM-4, produzido pela Sociedade Americana de Psiquiatria em 1994, que incluía a Síndrome de Asperger diferenciando-a da Síndrome de Kanner. O autor produziu uma analítica do TEA e dos Transtornos Globais do Desenvolvimento, mostrando que existe um importante acúmulo de pesquisas, sendo que estas trazem de certa forma os núcleos do transtorno propostos nas pesquisas da década de 1940, isto, é: "a) qualitativo da relação; b) alterações da comunicação e da linguagem; e c) falta de flexibilidade mental e comportamental" (RIVIÈRE, 2004, p. 238). Estes núcleos também são aceitos pelo Código Internacional de Doenças (CID-10) da Organização Mundial da Saúde (OMS), que tem sido adotado no contexto brasileiro. Recentemente o DSM-5, apresentado em 2013, definiu o TEA como uma condição neurodesenvolvimental que apresenta questões do desenvolvimento sociocomunicativo e comportamentos repetitivos com estereotipias, classificando três níveis de autismo, leve, moderado e severo, buscando englobar especificações da edição anterior como a Síndrome de Asperger (ALMEIDA et al., 2018). A semântica produzida nestas definições dialoga, ou não, com expressões cotidianas que articuladas também pelas lutas sociais dos próprios sujeitos, seus familiares e amigos, dentro do movimento das pessoas com deficiência (ROSA; MATSUKURA, SQUASSONI, 2019). Tanto as propostas diagnósticas como as posições das lutas do movimento social desses sujeitos procuram dar inteligibilidade a formas de vida historicamente atingidas pelo preconceito. Consideramos que essa inteligibilidade, principalmente na área da educação é fundamental para produção de estratégias que promovam o desenvolvimento integral dessas pessoas. Quando selecionamos determinada 
literatura e dialogamos com Rosa, nossa narradora, investigamos como as articulações discursivas produzem formas de inteligibilidade capazes de fornecer significados das pessoas com TEA e seu processo de desenvolvimento.

Compreendemos este desenvolvimento a partir dos domínios físico, cognitivo e psicossocial que estão interligados aos processos de desenvolvimento e aprendizagem, conforme definido na literatura (PAPALIA e FELDMAN, 2013). Nossa análise tem como pressuposto a importância dos processos de reconhecimento dessas pessoas como sujeitos de direitos no contexto educacional. A noção de reconhecimento indica um conjunto de práticas discursivas e enunciados em que certas formas de existência ganham inteligibilidade diante do coletivo, do outro e de si mesmo (BUTLER, 2015). Os discursos e enunciados que desclassificam e subalternizam as pessoas com TEA dizem de uma sociedade incapacitante, não raro deslocando as diferenças para os domínios de uma suposta anormalidade a ser sanada pelo modelo biomédico sustentado por compreensões capacitistas, estas ainda hegemônicas em nossa sociedade (MELLO, 2016).

O reconhecimento, na perspectiva por nós adotada, situa o sujeito nos territórios da diferença, e da legitimidade desta, nos ambientes de uma educação que se define como inclusiva e crítica a enunciados do capacitismo. Esse reconhecimento emerge em contextos que as relações de poder e resistência conseguem operar numa crítica a favor da diferença (CASTELO BRANCO, 2001) capaz de questionar uma sociedade hostil às diferenças ditas como deficiências e/ou transtornos do desenvolvimento. Com isto, não negamos a necessidade de assistência às pessoas com deficiência, mas problematizamos quando não se questiona os modos de vida de uma sociedade que não produz equidade na assistência das pessoas com deficiência. É importante salientar que nossa compreensão de sujeito se aproxima dos debates propostos por Foucault (2018), aqueles que propôs mais ao final de sua vida, principalmente na compreensão de agência nas ações de indivíduos e coletividades (BUTLER, 2015; CATELO BRANCO, 2001). Nesse período o autor passa "a estudar o papel das resistências em todas as suas dimensões, na trama complexa das relações de poder na atualidade, seus precedentes históricos e suas perspectivas de êxito" (CATELO BRANCO, 2001, p. 242). Por isso, acreditamos ser importante trazer algumas análises acadêmicas mescladas à narrativa de uma mãe de crianças com TEA, pois nessas análises é possível investigar a trama em que emergem os processos de reconhecimento.

Para isto realizamos um levantamento bibliográfico a fim de localizar análises sobre políticas públicas ou de direitos humanos relacionadas às crianças com TEA. Isto é algo que pode indicar formas de reconhecimento do sujeito e da importância do desenvolvimento psicossocial de crianças, com esse diagnóstico, em seu processo de escolarização. Além dos discursos institucionais também entendemos que o campo psicossocial se compõe pelas emoções, formação da personalidade e relações sociais (PAPALIA; FELDMAN, 2013), como aspectos que se relacionam intrinsecamente aos processos de subjetivação. Concordamos que certas dimensões da vida escapam ao discurso e podem apresentar outras formas de manifestação da verdade, principalmente na dimensão ética do sujeito (FOUCAULT, 2018). Por isso optamos pela entrevista narrativa com a mãe de duas crianças com Síndrome de Asperger, dentro do TEA; por coincidência essa mãe é professora da educação básica. No período da entrevista ela residia em uma cidade de pequeno a médio porte, na região central de Minas Gerais e foi selecionada a partir da rede de sujeitos que temos localizados em outras pesquisas. A escolha de alguém para uma entrevista narrativa, além de observar o envolvimento do (a) narrador (a) com o tema, deve verificar outros elementos como a capacidade de narração do sujeito, os 
vínculos de confiança com quem entrevista, bem como condições adequadas à realização do encontro (MUYLAERT et al., 2014; JOSSO, 2004).

Para a entrevista elaboramos as seguintes perguntas geradoras: como podemos pensar o desenvolvimento psicossocial das pessoas com deficiência no contexto escolar? Como familiares/cuidadores (as) de crianças com TEA têm percebido/acompanhado a vida escolar destas? Quais são os efeitos desta inclusão no processo de desenvolvimento psicossocial e educacional, na perspectiva de mães/cuidadores (as)? Ainda que, geralmente, se faça apenas uma questão, propomos a nossa narradora essas três num mesmo bloco. Também propusemos questões com termos mais elaborados considerando a formação de nossa narradora.

O desenho da pesquisa foi mais exploratório e ao final constatamos que diante dos discursos que desclassificam as crianças com TEA podemos observar formas de resistência. Estas parecem sustentadas pelos processos de reconhecimento da diferença nos domínios sociais, principalmente no contexto familiar. Todavia para isso se ampliar ainda é preciso que as escolas tenham condições de recepcionarem de forma mais efetiva os direitos proclamados em instrumentos de direitos humanos e normativas das políticas públicas. Isto se relaciona a uma perspectiva das lutas de pessoas com deficiência nas políticas de direitos humanos, "nada sobre nós, sem nós" (RIOS, 2017) ${ }^{4}$. Para um desenvolvimento psicossocial das crianças com TEA consideramos fundamentais esses processos de reconhecimento nas interdependências sociais, algo que Papalia e Feldman (2013), analisam no trecho a seguir.

O desenvolvimento psicossocial pode afetar o funcionamento cognitivo e físico. De fato, sem conexões sociais significativas, a saúde física e mental terá problemas. A motivação e a autoconfiança são fatores importantes para o sucesso na escola, enquanto emoções negativas como a ansiedade podem prejudicar o desempenho. Pesquisadores chegaram a identificar possíveis ligações entre uma personalidade conscienciosa e a duração da vida. Inversamente, as capacidades física e cognitiva podem afetar o desenvolvimento psicossocial, além de contribuir significativamente para a autoestima e poder afetar a aceitação social e a escolha profissional. (PAPALIA e FELDMAN, 2013, p. 38).

Em certa medida, podemos dizer que nossa narradora, como mãe de crianças com a Síndrome de Asperge, diante do preconceito e/ou desconsideração dos direitos de seus filhos, tem sido capaz de operar formas de resistência ao elaborar uma crítica ao contexto social e de forma específica às lógicas escolares. Isto se dá principalmente na elaboração de estratégias que sustentam seus filhos no processo de escolarização.

\section{CAMINHOS DA PESQUISA}

Para atender ao objetivo proposto nesta pesquisa foram realizadas três etapas. A primeira consistiu na realização de um levantamento bibliográfico em algumas bases de publicações científicas: o Portal

\footnotetext{
${ }^{4}$ Observamos que recentemente os argumentos do lema "Nada sobre nós sem nós" - foi utilizado para aprovar o Decreto de 10.502/2020 (BRASIL, 2020) que prejudicou, em certa medida, o reconhecimento das pessoas com deficiência. Neste decreto se coloca que as famílias devem escolher entre educação especializada e/ou a educação regular. No atual contexto das políticas de direitos humanos a educação regular tem sido compreendida como um direito da pessoa com deficiência e não uma opção que faculta a família. É um tema que produz muitos debates e ainda está em andamento. Isto não retira o valor da análise dessa questão pelo texto, mas coloca uma problematização.
} 
Scielo (Scientific Electronic Library Online) e o Portal de Periódicos Capes. Nessas plataformas de pesquisa, buscamos principalmente artigos pertinentes ao escopo de nossa pesquisa. Posteriormente, foi realizada a leitura dos resumos e das palavras-chaves dos textos encontrados, adotando como critério de seleção, apenas o conteúdo exposto, isto é, verificou-se quais foram os artigos que atendiam a perspectiva da pesquisa. Os textos utilizados muitas vezes traziam nas referências alguns trabalhos que consideramos importantes e por isso apropriados na pesquisa. Vale destacar que os estudos selecionados foram utilizados para a construção dos argumentos da pesquisa, não havendo uma análise pormenorizada e individualizada dos textos ao longo desta pesquisa.

No segundo momento, da pesquisa, foi realizada a entrevista narrativa com a mãe das duas crianças que possuíam diagnóstico de Síndrome de Asperger, conforme já mencionado. Essas crianças eram estudantes em uma escola pública municipal. Para realizar esta entrevista, foi lido para entrevistada o Termo de Consentimento Livre e Esclarecido para gravar e fazer uso das informações para pesquisa acadêmica. Depois de sua concordância procedemos a entrevista. Foram seguidos todos os procedimentos aprovados pelo Comitê de Ética da universidade.

Muylaert et al. (2014) afirmam que essa modalidade de entrevista se caracteriza de maneira mais fluída e como ferramenta não estruturada, ela visa a profundidade de aspectos específicos que possibilitam a emergência das histórias de vidas dos sujeitos. A entrevista narrativa busca encorajar e estimular o sujeito a contar algo sobre algum acontecimento importante de sua vida e/ou do seu contexto social. Tal modalidade de entrevista pode permitir o aprofundamento das investigações, a combinação de histórias de vida com contextos sociais e históricos, tornando possível a percepção dos sentidos e a reflexão sobre os acontecimentos passados. O que pode, segundo Josso (2004), contribuir para ressignificar a identidade e subjetividade de quem fala. A partir do próprio ato de narrar, o sujeito se apropria do seu processo de formação e da sua trajetória. Para Passeggi (2016), no relato a voz do sujeito revela o seu cotidiano, as suas lembranças e os seus valores, na busca de compreender os seus sentidos, suas vivências e suas experiências.

Por fim, consideramos que a entrevista narrativa é importante para o desenvolvimento da pesquisa, mas também como possibilidade de o narrador elaborar suas aprendizagens, perceber da sua forma de articular nas relações sociais e produzir reconhecimento sobre si mesmo. Assim, a narrativa pode se constituir como uma experiência significativa nos processos de subjetivação de quem relata, uma possibilidade de organização de seu mundo.

\section{RECONHECIMENTO DOS CORPOS MARCADOS PELA DIFERENÇA NOS DOMÍNIOS DA EDUCAÇÃO}

A concepção de deficiência se constitui por discursos e práticas sociais sobre o corpo e a sua forma idealizada colocada como mais desejável em diferentes domínios. Silva, Priszkulnik e Herzberg (2018) questionam os pressupostos ontológicos e práticas de tratamentos atribuídos ao corpo deficiente, principalmente questionando a compreensão de que a deficiência traz prejuízo aos corpos. Esses autores analisando a compreensão do corpo em diversos contextos históricos, afirmam como a cientificidade contemporânea produz um forte discurso sobre um corpo normal e saudável, sem questionar os problemas desse discurso. Isto se dá dentro de um contínuo entre polos definidos como normal e anormal, ou termos similares, geralmente por uma linguagem controlada pelos diagnósticos do discurso das ciências médicas. Nesse contexto temos os discursos que produzem formas de inteligibilidade ao corpo da pessoa com deficiência. 
Para a filósofa Judith Butler (2015), orientada pela perspectiva foucaultiana, a inteligibilidade do sujeito se constitui a partir de um conjunto de normas sociais e culturais estabelecidas na relação com a coletividade, com o outro e com o "eu". Esse reconhecimento se dá em processos em que a voz do sujeito que relata a si mesmo, sua história, seus sofrimentos e desejos, produz uma reflexividade que instaura uma Ética no contexto da narrativa. Todavia, o reconhecimento sempre ocorre marcado pela opacidade das posições discursivas, afinal, na voz de quem relata encontramos a voz do outro e da comunidade, em imbricações nem sempre possíveis de distinção (BUTLER, 2015). Por esse relato de si o sujeito se constitui dentro de uma inteligibilidade que determina quais corpos são passíveis de serem humanizados ou não. Nossa narradora está na posição de um outro diante de seus filhos, diagnosticados com TEA, sua narrativa nos indicou como o reconhecimento se tece como uma trama onde afetos, afirmação dos direitos e estratégias de luta se constituem como formas de resistência, fundamentais nos processos de reconhecimento. Qual a resistência que aparece nas posições dessa mãe? Ela resiste ao poder desses discursos capazes de constituírem uma vida precária (BUTLER, 2011), essa precariedade induzida é capaz de estabelecer relações que produz corpos não inteligíveis. Estes, por vezes, o discurso nem alcança e sem vinculações inteligíveis são relegados ao inumano. A pessoa com deficiência, não raro, é produzida nos domínios de uma vida precária, de diferentes modos, em contextos históricos específicos.

Pesquisas sobre a escolarização de pessoas com deficiência, pontua críticas ao sistema de educação especial. O estudo de Castro (2013) considera que a criação de associações e escolas especiais no Brasil reforçou a institucionalização de uma escolarização segregacionista, ao invés de inclusiva. Podemos considerar que esse processo de institucionalização ainda persiste de formas renovadas com certos argumentos do Decreto 10.502 (BRASIL, 2020). Alguns pesquisadores, como Mantoan (2003), ao relatarem a realidade no processo de matrícula de alunos com deficiência, salienta que há uma resistência de as escolas regulares incluírem pessoas com deficiências. O não reconhecimento da pessoa com deficiência como sujeito capaz de aprender pode gerar uma inclusão sem permanência ou uma escolarização sem aprendizagem, algo que afetará de modo contundente topo o desenvolvimento psicossocial da criança. Também se pode observar que estas instituições de ensino regular muitas vezes não se dispõem a rever sua estrutura física, organizacional e educacional, que recepcione um currículo receptivo a uma prática de ensino que atenda a diversidade que ela deveria atender (PLAISANCE, 2015).

Mantoan (2003) e Sassaki (2009) confirmam que, a inclusão ainda não está sendo colocada em prática nos sistemas de ensino, ainda que parâmetros legais assegurem à criança com deficiência o direito à educação. Aqui devemos compreender que o reconhecimento coletivo não se resume as normativas legais ou mesmo morais. O reconhecimento se dá pelas relações de poder e resistência orientadas por verdades mais ou menos marcadas pela racionalidade. Foucault (2018) aponta como essas verdades são capazes de conduzir a conduta dos grupos, do outro e de si mesmo, algo que ele define pela noção de governo. Esta não indica as esferas estatais da administração, mas indica um quadro de referências pelos quais nos movemos, isto é, por verdades capazes de governar as formas de existência. Desse modo, pode-se analisar que a sociedade, como dimensão coletiva do reconhecimento, não é capaz de produzir formas inclusivas para o governo dos corpos no contexto educacional de modo mais efetivo. Coloca-se, assim, uma importante questão sobre o reconhecimento de pessoas com deficiência, conforme aponta Butler num diálogo com Sunaura Taylor (2008): "como promover uma educação inclusiva se a sociedade é incapacitante?" No documentário Examined Life (TAYLOR, 2008), um dos episódios consiste em uma conversa de Judith Butler e Sunaura Taylor, ativista americana dos direitos das pessoas com deficiência, que ao nascer 
foi diagnosticada com Artrogripose5. Ao relatar sobre o processo de inclusão e sobre os efeitos incapacitantes da sociedade, Taylor explicita que,

[...] a deficiência é basicamente a repressão social das pessoas com deficiência. 0 fato de que as pessoas com deficiência têm opções de habitação limitadas; nós não temos oportunidade de carreira e nós somos, socialmente, isolados. Somos, você sabe, em muitas maneiras, há uma aversão cultural às pessoas com deficiência. $(2008, \mathrm{~s} / \mathrm{p})$.

Temos assim a formação de enunciados que afirmam ser toda pessoa com deficiência incapaz de desenvolver plenamente o seu desenvolvimento psicossocial. Isto advém de um discurso reducionista sobre as pessoas com deficiência, esse discurso produz uma força que pode subjugar esses sujeitos. Todavia, como relata Taylor (2008), ela não se contentou com esse lugar e por volta dos vinte anos de idade passou a frequentar lugares públicos e intensificar suas lutas pela inclusão social. Vemos assim, que as relações de poder e resistência ocorrem numa trama que se revela em cada situação de modo muito próprio em diferentes contextos.

Ao longo da história, e de modo mais significativo, no século XX as compreensões sobre pessoas com deficiência sofreram muitas mudanças, desde àquelas que produzem o corpo com deficiência como se fosse resultado da ira divina até outros que constituíam este corpo no registro das incapacidades. Este se tornou predominante em nossa sociedade, ainda que outras formas de compreensão resistam no imaginário social (GOMES; LOPES; GESSER; TONELI, 2019; GAUDENZI; ORTEGA, 2016). As formas de reconhecimento das pessoas com deficiência, durante o século $X X$, se estabeleceram em meio a movimentações importantes que têm deslocado a linguagem das deficiências para compreensões de uma sociedade e escola que sejam mais inclusivas (MARCHESI, 2004).

Considerando o período de duas décadas, de 1970 a 1990, tem-se, em 1973, a criação do primeiro órgão federal de política para alunos portadores de deficiência, o Centro Nacional de Educação Especial (CENESP). A partir do ano de 1981, conhecido como "Ano Internacional das Pessoas com Deficiência", são traçadas metas que alicerçarão as políticas públicas brasileiras de inclusão; e, em 1994 a Conferência Mundial sobre Necessidades Educativas Especiais promovida pela Organização das Nações Unidas para Educação, ciência e cultura (UNESCO), culminou na elaboração da "Declaração de Salamanca", documento que embasa o movimento pela inclusão de pessoas com deficiência. (ROSA, MATSUKURA e SQUASSONI, 2019, p. 309).

Consideramos que os significados socialmente produzidos desdobraram em modos de subjetivação nos domínios do TEA. Podemos dizer que existe contexto que tem revelado o rosto das pessoas com deficiência, produzido formas de reconhecimento que no embate das forças que produzem a trama de poder e resistência. Butler (2011) utiliza a noção de rosto em Emanuel Levinas para pensar a vida precária; nesse autor o rosto não se trata da face, mas das marcas de sofrimentos, das cicatrizes que carregam um corpo e podem não serem percebidas pelos demais.

Para Levinas, portanto, o humano não é representado pelo rosto. Pelo contrário, o humano é indiretamente armado exatamente nessa disjunção que torna a representação impossível, e essa disjunção é exprimida na representação impossível. Para a representação exprimir o humano, portanto, ela deve não apenas falhar, mas deve mostrar sua falha. Há algo de irrepresentável que

\footnotetext{
${ }^{5}$ Síndrome rara que constitui um grupo heterogêneo de malformações congênitas de caráter estacionário e etiologia desconhecida, provavelmente multifatorial, caracterizada principalmente por severas contraturas articulares (SACCANI; UMPIERRES; BASEGIO, 2008).
} 
nós, não obstante, perseguimos representar e esse paradoxo deve ser absorvido nas representações que realizamos (BUTLER, 2011, p. 27).

A sociedade ainda conhece pouco o rosto, isto é, as cicatrizes que marcam a existência de uma pessoa com TEA. Sem isto, dificilmente se produzirá formas possíveis para que o reconhecimento dê sentido à existência dessas formas de existência. No contexto do século XX emerge um importante enunciado na cena do reconhecimento das pessoas com deficiência, "nada sobre nós, sem nós" (RIOS, 2017). Esse enunciado, com as possíveis contradições em seus usos, produz um imperativo ético para políticas de direitos humanos, políticas públicas, saberes e fazeres da Educação, enfim, para a sociedade como um todo. Evidentemente esse enunciado, como outros instrumentos de direitos humanos, visa mais denunciar a negligência social e/ou estatal em relação às pessoas com deficiência do que constatar uma realidade e/ou normatizá-la. Todavia, a produção dos discursos no campo dos direitos humanos ganhou importância na compreensão daquilo que entendemos por inteligibilidade do corpo da pessoa com deficiência nos domínios da diferença.

Essas políticas de reconhecimento são importantes à constituição da mudança de atitude em relação à criança com TEA, pois no contexto da educação inclusiva, pode gerar um contato importante e privilegiado entre essa criança e os demais participantes da comunidade escolar, como aponta Mantoan no trecho abaixo.

[...] a inclusão escolar envolve basicamente, uma mudança de atitude face ao Outro: que não é mais um, um indivíduo qualquer, com o qual topamos simplesmente na nossa existência e com o qual convivemos um certo tempo, maior ou menor de nossas vidas. O Outro é alguém que é essencial para nossa constituição como pessoa e dessa Alteridade é que subsistimos, e é dela que emana a Justiça, a garantia da vida compartilhada. (MANTOAN. 2003, p. 81).

Para Freud (1930) o nosso ego, ou o nosso eu, é a somatória de objetos fracionados, estando sempre em função de outras pessoas. Nesse argumento freudiano está sustentada parte da noção de reconhecimento e opacidade de Butler (2015). Dessa forma, a saúde mental do sujeito não pode prescindir da existência de laços sociais (RAHME, 2010) suficientemente bons, pois por estes será possível a produção de uma inteligibilidade nas interdependências sociais. Uma vez que os laços ou vínculos sociais são fundamentais para todas as pessoas, e a ausência deles, segundo Freud (1930) está relacionada ao adoecimento. Diante de tais questões ganha gravidade a necessidade de reconhecimento desses sujeitos.

Segundo Rahme (2010), é por meio do discurso que se concebe as relações sociais, uma vez que o outro é aquele a quem o discurso se direciona, e assim se constitui os laços sociais e consequentemente os sujeitos. Ainda, de acordo com Rahme (2010), o laço social como discurso, portanto, é um pensamento sobre as maneiras que os seres criam os seus vínculos, pela experiência e pela possibilidade da busca de gozo e no necessário reencontro com seu fracasso. Para Herzog (2004), o laço social também está diretamente ligado ao desejo de identificação e reconhecimento subjetivo dos sujeitos. Por isso, acreditamos que a narrativa da mãe entrevistada em nossa pesquisa, além de indicar as formas de resistência contra uma precarização da vida de seus filhos, produz para eles processos de identificação e reconhecimento subjetivo.

No processo de constituição da inclusão escolar, principalmente nos contextos da educação especial, a relação família-escola é fundamental nos processos de reconhecimento. Para a construção da identidade, autonomia e cidadania de estudantes é fundamental a construção de parcerias entre a família e a escola à promoção do desenvolvimento do alunado (MATOS et al., 2017), em especial 
para as pessoas com deficiência. A criança passa a fazer sentido para si, para o outro e para a coletividade nas interdependências sociais, nestas pode se estabelecer relações significativas para sua constituição como sujeito, algo que as pesquisas sobre o laço social têm indicado (GRUDZINSKI, 2009; RAHME, 2010). Certamente é nessa perspectiva que emergem os impactos das relações familiares com as questões da aprendizagem das crianças. A pesquisa de Rosa, Matsukura e Squassoni (2019) apresenta relatos de familiares que reconhecem o período escolar como contexto que apresenta ganhos para pessoa com TEA. Essas pesquisas também apontam a dificuldade de as pessoas com deficiência acessarem e permanecerem nas escolas devido aos preconceitos e barreiras sociais, algo que gera apreensões e ansiedade na vida das pessoas.

Consideramos que pesquisas, normatizações de políticas públicas, orientações no campo de direitos humanos constituem um contexto fundamental na produção do reconhecimento de crianças ditas com TEA, pois parecem produzir efeitos na educação. Consideramos que esse contexto tem produzido formas de resistência ao poder dos discursos que fazem as pessoas com deficiência experimentarem uma vida precária. Pela entrevista narrativa, também analisamos como isto pode ser observado nos processos de inclusão escolar na rede de ensino de uma cidade do interior de Minas Gerais. Assim investigamos a importância da relação entre família e escola, como uma parceria que ainda precisa ser consolidada, pois a consideramos um elemento fundamental para 0 desenvolvimento psicossocial e educacional do alunado com TEA.

\section{RELAÇÕES DE PODER E RESISTÊNCIA NA LUTA DE UMA MÃE PELA EDUCAÇÃO DE SEUS FILHOS}

As três dimensões do reconhecimento, isto é, o outro, o coletivo e o si mesmo, não operam de modo autônomo ou facilmente distinguíveis, mas certamente ocorrem nas tramas em que poder e resistência se constituem. Ao trazer alguns elementos da entrevista narrativa analisamos como as formas de reconhecimento das pessoas com deficiência nas políticas públicas e de direitos humanos reverberam nos contextos da vida de cada sujeito e vice-versa. Rosa, quem concedeu a entrevista narrativa, como já mencionado, é professora e possui dois filhos diagnosticados com a Síndrome de Asperger. Para preservar o anonimato dessas pessoas temos utilizado o pseudônimo de Rosa para a mãe, de Luiz e Pedro para os filhos. Essa síndrome passa a constar dentro do TEA a partir da quinta edição do DSM (Manual Diagnóstico e Estatístico de Transtornos Mentais) (ALMEIDA, et al., 2018; ROSA, MATSUKURA, SQUASSONI, 2019). Na quarta edição revisada deste manual essa síndrome era considera uma variante do autismo (KLIN, 2006) dentro da categoria dos transtornos invasivos do desenvolvimento (TID). Consideramos que o diagnóstico pode ser uma captura de educadores (as), de familiares das pessoas com deficiência, entre outros, ainda que não necessariamente. Todavia, reduzir o sujeito a seu diagnóstico indica a força do discurso médico-psiquiátrico, que nos arrasta muitas vezes para as lógicas da medicalização da vida e da sociedade (COLLARES; MOYSÉS, 1994). Por isto, urge pensarmos o TEA além desse contexto do diagnóstico, algo que propomos no presente artigo. Aqui não desprezamos o conhecimento das ciências médicas, mas tomamos de forma crítica suas definições. Afirmamos que o desenvolvimento de uma pessoa com deficiência implica questões éticas, políticas econômicas etc. A semântica desses transtornos ainda possui questões em elaboração, mas consideramos bastante pertinente a análise que segue.

Os Transtornos do Espectro Autista (TEA) designam os Transtornos: Autista, Asperger e Transtorno Global do Desenvolvimento sem Outra Especificação, sendo que as variações são denominadas conforme o nível de gravidade. Estes transtornos se 
caracterizam pela apresentação de déficits persistentes na comunicação social e na interação social, bem como a presença de comportamentos, atividades e interesses restritos e repetitivos, características que devem estar presentes desde cedo no desenvolvimento da criança, levando a prejuízos sociais, ocupacionais e outros. (ROSA, MATSUKURA e SQUASSONI, 2019, p. 303).

Todavia, com essa definição, há que se produzir formas potentes de resistência para não reduzir vidas humanas a um diagnóstico. As pessoas diagnosticadas com a Síndrome de Asperger são descritas como possuidoras de uma linguagem "superficialmente" corretíssima, pedante, com formulações complexas, com algumas pragmáticas; também pode ter "inteligência impessoal fria" e frequentemente extraordinária em campos restritos (RIVIÈRE, 2004). No caso em estudo, Pedro, 0 filho mais velho, foi diagnosticado equivocadamente com epilepsia e tomava os medicamentos, Gadernal e Depaquine, que trouxeram alguns prejuízos ao seu processo de aprendizagem. Esse equívoco pode se relacionar ao processo de medicalização em que os diagnósticos podem ser apressados em favor dos lucros de uma poderosa indústria farmacológica, ainda que o medicamento não seja um problema em si (MEIRA, 2012). Depois de algum tempo, foi constatado que Pedro possuía a Síndrome de Asperger e Erros Inatos do Metabolismo, conforme relato de sua mãe. Luiz, o filho mais novo, também foi diagnosticado com Asperger, com um grau diferente de seu irmão mais velho.

O relato de Rosa pontua o quão difícil foi encontrar uma escola que oferecesse os suportes necessários para possibilitar a plena aprendizagem de ambos os filhos. Em sua narrativa foi ressaltada a dificuldade de o sistema de ensino propiciar condições basilares para Luiz, o mais novo, como por exemplo, a presença de um professor auxiliar em sala de aula. Rosa relatou que foi uma experiência muito dolorosa e demorada, em virtude da intervenção judicial necessária à defesa do direito de seu filho à educação. Na descrição de nossa narradora vemos operar o poder do discurso que exclui e incapacita as pessoas marcadas pela diferença, porém vemos como o reconhecimento coletivo produziu inteligibilidades capazes de articularem formas de resistência para uma mãe que luta pelo direito à educação de seus filhos. Rosa, além da formação como professora possui mestrado em Educação, quando se dedicou a pesquisar questões da educação especial. Segundo Capellini (2001) a presença de um professor auxiliar se faz importante para se ter uma inclusão com qualidade, desde que o ensino seja pautado no cooperativismo, isto é, os docentes se proponham a planejar e efetuar novas práticas educativas que busquem a plena aprendizagem de estudantes com necessidades educacionais especiais. A mistura de preconceito e barreiras sociais para pessoas diagnosticadas com TEA (ROSA; MATSUKURA; SQUASSONI, 2019) são forças que colidem com o afeto e o cuidado de Rosa para com Pedro e Luiz. A verdade que governa as condutas de Rosa, suas formas de resistência dizem de uma racionalidade das leis e dos instrumentos de direitos humanos, mas não se resume a esta. A verdade de nossa narradora, sobre seus filhos, se alimenta também das emoções e afetos de uma mãe que ama seus filhos, isto nos indica que as relações entre poder e resistência possuem componentes não necessariamente forjados por uma racionalidade. As relações de poder podem produzir uma indução da precariedade de existências como as de Luiz e Pedro, certamente constituindo processos de subjetivação em que o reconhecimento dessas crianças sofre danos. É importante notar que o apelo a judicialização possibilita um acesso formal, mas pode ser insuficiente ainda, pois nada garante que no cotidiano da escola a diferença da síndrome seja ressignificada, algo que se explicita na entrevista narrativa.

[...] nenhum investimento era feito pela equipe de professores e pedagogos. Absolutamente nada. Ele ia para escola apenas para se socializar. Não formulavam provas, exercícios e o aprovava para obedecer a lei. Foi assim até o $9^{\circ}$ ano. [...] A 
única assistência diferenciada que recebia no ambiente escolar era tempo estendido para fazer provas, pois ficou com sequelas motoras que lenificavam os movimentos. (ROSA, 2018, p. 2).

Estas descrições são de momentos diferentes da formação de Pedro e Luiz, mas indicam como se mesclam elementos discursivos de diferentes ordens na produção do reconhecimento. Os relatos de Rosa possuem uma capacidade analítica, provavelmente devido sua formação como professora, mas sobretudo, pela verdade que conduz sua vida, isto é, o direito de seus filhos à educação. A desconsideração da singularidade de Pedro e Luiz nos territórios da escola indicam como se dá a produção de uma vida precária. Ainda que todos (as) nós experimentemos a experiência de uma precariedade própria da existência, consideramos que a precariedade aqui é aquela induzida por relações de poder que classificam alguns corpos como desimportantes (Butler, 2015), corpo negligenciáveis num processo de subalternização em que temos prejudicadas as possibilidades de reconhecimento diante do coletivo, do outro e de si mesmo. Pensar nos processos de reconhecimento é um exercício para se pensar o sujeito diagnosticado com TEA além das questões médicas, mas priorizando também as sociais, além de outras, que serão fundamentais para o desenvolvimento psicossocial desses sujeitos.

Zanellato e Poker (2012) afirmam que é possível garantir uma educação de qualidade se considerada as especificidades de cada educando. Nesse sentido, é importante que o (a) professor (a) busque informações para estar ciente das habilidades e dificuldades que a criança com TEA apresenta e faça uso destas informações para planejar e executar práticas pedagógicas que podem propiciar avanços significativos no processo de aprendizagem.

Segundo Prioste (2006), no contexto da Educação Inclusiva, existe uma dificuldade para o estabelecimento de laços entre professores (as) e alunos (as), e tal dificuldade decorre da precariedade nas condições de trabalho e de estereótipos criados acerca da criança considerada "diferente". Os (as) profissionais da educação também podem aprender com as crianças com deficiência e desenvolver habilidades para lidar com situações semelhantes envolvendo outras crianças. A importância da relação estabelecida entre a professora e o aluno pode ser notada na fala de mãe.

\footnotetext{
Ele gosta muito e este ano eu consigo ver que está um pouco melhor, eu vejo que a professora é interessada, ela estuda, ela lê, ela procura mais informações. E na sala do Luiz na verdade, nós suspeitamos que tenha mais dois com autismo, e foi através do Luiz, do que ela buscou para o Luiz, o que ela pesquisa para ele, ela consegue passar para os demais alunos. O Luiz quando entrou na escola regular, tinha a fala muito atrasada e restrita, e hoje ele consegue se comunicar com mais facilidade, ele desenvolveu muito de julho para cá, hoje ele consegue se expressar, ele fala as suas vontades, e me contar as coisas. (ROSA, 2018, p. 1).
}

A resistência ao assujeitamento das crianças com TEA também emergem em posições como desta professora e, certamente, de outras pessoas do ambiente escolar. Para que a relação entre professor (a) e o (a) aluno (a) com deficiência aconteça de forma satisfatória, a formação acadêmica do (a) profissional que atua com a inclusão é essencial. Segundo Barbosa e Conti (2011), esses (as) profissionais precisam levar em consideração os conhecimentos teóricos e técnicos para atender esses alunos. Os cursos de graduação, principalmente os de licenciatura, também devem ser capazes de criar artifícios teóricos e práticos para formação de professores (as), pois dessa forma se produz uma escola que recepcione e promova o desenvolvimento do alunado como um todo. Podemos perceber tal importância da fala de Rosa. 
Está caminhando. Acho que está longe, muito longe ainda de acontecer, principalmente quanto assim, a formação de professores. Muitos professores ainda não enxergaram que existe uma educação inclusiva. Não enxergaram que em uma sala de 25 alunos, 5 estarão em uma educação inclusiva. (Rosa, 2018, p. 1).

Além das questões com o professorado temos as relações com os colegas em sala de aula. Nesse contexto o reconhecimento entre pares é de extrema importância como uma possibilidade de se viver no espaço escolar experiências que podem se desdobrar em outros domínios da existência. A importância desse convívio pode ser observada na fala de nossa narradora.

Os coleguinhas da nova escola agora que estão percebendo que o Luiz é diferente e todos têm um tratamento muito especial com ele, muito carinhoso. Ele foi muito bem aceito por todos, ele é que eu acho que escolhe, tem dois colegas que eu sempre vejo com ele, a relação e a interação que é própria dele, mas não são os outros alunos, é uma característica dele. (ROSA, 2018, p. 2).

Assim, percebe-se quanto o tratamento dos (as) demais alunos (as) influenciou para que a criança estivesse efetivamente num processo de inclusão, onde ele se sentiu aceito, conseguindo estabelecer vínculos com dois colegas em específico. Nessa dinâmica Rosa constata em Luiz característica próprias dele, o singulariza em meio aos demais, produz formas de reconhecimento de suas potencialidades para o desenvolvimento psicossocial. A relação entre a família e a criança pode sofrer influência a partir do seu ingresso no ensino regular pois, ao interagir com outras pessoas, o sujeito amplia seu campo de socialização se tornando mais aberto a novas interações. Assim, quando Luiz passa a contar "historinhas" sobre a escola, produz um reconhecimento de si como aluno, como sujeito da aprendizagem e não com sujeito submetido à deficiência.

Ele desenvolveu muito como sujeito, hoje ele fala, hoje ele expressa os pensamentos dele. Hoje ele consegue chegar em casa e me dizer como foi na escola, me passar se tem algum bilhete ou alguma informação, e isso para mim é muito importante. Hoje ele consegue me falar dos "coleguinhas", ele me conta as coisas, me conta "historinhas". (ROSA, 2018, p. 2).

Para além da atuação dos profissionais da educação, os relatos demonstram que a prática familiar pode ser elementar para a conquista de ganhos expressivos no processo de desenvolvimento cognitivo, socioeducacional e psicológico da pessoa com TEA.

[...] é muito importante que haja uma parceria entre familiares e escola, pois os pais são portadores de informações preciosas que podem colaborar bastante com o planejamento das intervenções educacionais das crianças portadoras de autismo, especialmente pela peculiaridade da forma de comunicação dos portadores dessa síndrome. (SERRA, 2004, p. 25).

Certamente que as lutas de Rosa foram catalizadoras para os processos de reconhecimento na escola, mas é imperativo que as trocas entre família e escola aconteçam efetivamente. Também é de grande importância que essas crianças tenham outras possibilidades de aprendizagem além da escola. Nossa narradora menciona que para impulsionar a evolução da aprendizagem dos dois filhos fez uso de musicoterapia, musicalização, fonoaudiologia, terapia ocupacional, professores particulares, presença de psicopedagogos, psicólogos, equoterapia, natação, karaté e taekwondo. Tais mecanismos, usados para a aprendizagem, foram imprescindíveis para que o filho mais velho, Pedro, alcançasse uma vaga no curso de Administração, em um centro universitário de Belo Horizonte. Também foram recursos importantes para desenvolver algumas habilidades do filho mais novo Luiz, que diferente do mais velho, apresenta uma variação mais acentuada de condições psicomotoras e cognitivas, que se refere ao grau diferenciado da Síndrome de Asperger. 
Vale ressaltar, que ao longo da análise dos resultados desta pesquisa ficou perceptível o quão importante se faz as condições sociais e econômicas que a família de Rosa tinha acesso. Isto se mostrou crucial tanto para reivindicar os direitos dos filhos em ter acesso a educação de qualidade, como também, identificar e acompanhar criteriosamente o processo de ensino-aprendizagem de seus filhos (MATOS, et al., 2017). Por outro lado, podemos considerar que as condições das escolas, da formação do professorado, bem como o suporte legal dado pelas políticas, compõem as tramas produzidas pelas relações de poder e resistência no processo de reconhecimento de Pedro e Luiz como sujeitos de direitos. Certamente poderíamos pensar nos efeitos desses processos na vida de ambos, considerando que atualmente Pedro curso o ensino superior.

Quando relacionamos as formas de existência de pessoas com TEA e a teoria de Butler, em seu texto Vida Precária (2011) consideramos a importância de pensamos os processos de subjetivação daquelas. Deste modo, nos ocupamos com a dimensão ética do reconhecimento dessas pessoas e de seus direitos nas interdependências sociais. Nesse contexto, avaliamos como importante questionarmos em que medida a pessoa com TEA consegue se reconhecer e ser reconhecida, focando em sua condição de sujeito que precisa a todo instante negociar sua existência, sua acessibilidade no âmbito educacional, político e social para ser reconhecido como humano. A este ponto não avançamos, mas buscamos identificar a importância da resistência nos processos de reconhecimento de modo mais amplo. Butler (2015) ressalta que precisamos nos responsabilizar pelo outro, estabelecendo uma relação de reconhecimento, que pode o levar ao exercício da ética a partir do encontro com o outro. Isto exige irmos além das máximas morais anacrônicas que se tornaram incapazes de dar sentido as estas existências marcadas pela diferença. Isto ainda nos deixa algumas questões. Será que as definições do TEA, produzidas nas interdependências sociais, são capazes de dar sentido a vida de uma criança? Em nossas análises respondemos em parte a seguinte questão. Como essa criança se insere e é significada nos discursos de seus círculos de convivência, especificamente a relação com a família e a escola?

Consideramos que nesses círculos o sujeito pode ser reconhecido em sua trajetória, principalmente o rosto da criança com TEA. Neste processo de reconhecimento os limites entre o relato de si e do outro possuem zonas interseccionadas. O reconhecimento do rosto de crianças como Luiz e Pedro está estritamente relacionado aos relatos que emergem em suas vidas, na capacidade de mães como Rosa, trazerem relatos que nos apresentem a existência dessas crianças.

\section{CONCLUSÃO}

A partir de nossa pesquisa consideramos que as relações de poder e resistência são fundamentais à produção de inteligibilidade sobre determinadas formas de existência nos domínios do TEA. Tal inteligibilidade está atrelada aos processos de reconhecimento da vida das pessoas com deficiência diante do coletivo, do outro e de si mesmo. Determinados discursos da pesquisa acadêmica, das políticas públicas e das lutas sociais, afinados no diapasão do reconhecimento da diferença, podem sustentar de modo satisfatório o processo de inclusão e desenvolvimento psicossocial das crianças com deficiência. Esta dificuldade do reconhecimento não está imersa somente na displicência das instituições de ensino, sobretudo em reformular sua receptividade às diferenças, promovendo as mudanças necessárias para atender ao público que se propõe a acolher e escolarizar. Também está correlacionada com a perspectiva de discursos que produzem uma sociedade incapacitante, que produz formas de existência como vidas precárias. Os discursos e práticas sociais que tornam 
precárias suas formas de existências produzem uma gramática do assujeitamento e da exclusão dos espaços sociais, prejudicando a participação social, cultural e política os sujeitos marcados por determinadas diferenças.

Nesse contexto, grupos de pessoas com TEA e seus familiares, entre outras diferenças ditas como deficiência, têm se mobilizado de diversos modos, produzindo outras semânticas no campo das lutas sociais, pesquisas acadêmicas e políticas de direitos humanos (MARCHESI, 2004; RIOS, 2017). Esses grupos e pessoas são movidos por desejos que os organizam politicamente para disputar pelos espaços sociais, como como faz Rosa e Sunaura Taylor. Vale ressaltar, que neste processo a escola é um cenário das relações de poder e resistência. No contexto escolar temos a re/produção de desigualdades como também saídas e possibilidades de reconhecimento, para isto a formação de professores (as) ganha destaque, as condições materiais dos estabelecimentos escolares tornam-se prioridades e a audição dos sujeitos das diferenças é fundamental.

Rosa, a narradora de nossa pesquisa, tem sido produzida como uma mãe que traz para sua existência as lutas sociais, o conhecimento de sua formação como professora e a semântica das políticas de direitos humanos na defesa que faz de seus filhos. Ao recorrer à justiça contra a exclusão de seus filhos, ao afirmar o direito deles a uma educação de qualidade, o acompanhamento escolar que faz de seus filhos, enfim, ao se propor em relatar suas experiências para nós, ela certamente contribui para que os processos de reconhecimento não se constituam na lógica que induz sujeitos à precariedade pelos discursos capacitistas. A narrativa dessa mãe nos revelou uma capacidade de deslocamento da existência de seus filhos dos processos de medicalização da vida para o reconhecimento deles como sujeitos de direitos. Por ela é possível entender que nada sobre eles sem eles, ainda que as nuances da síndrome fossem diferentes em cada um deles e apresentassem questões específicas. Não reduzir a criança com TEA à seu diagnóstico nos domínios da família se mostrou capaz de mobilizar outros contextos.

Uma escola inclusiva implica que todas as crianças possam aprender, com qualidade, e que possam fazer parte da vida escolar e social. Dessa forma, é necessário refletir como tornar as escolas mais inclusivas. Não é possível formular uma resposta simplória a esta questão, mas podemos, por meio dos resultados apresentados nessa pesquisa e em outras, afirmar que parte da resposta consiste em produzir condições para o reconhecimento das pessoas com deficiência, considerando suas diferenças e singularidades. Luiz e Pedro, mesmo partilhando o mesmo diagnóstico, apresentavam dentro do TEA características individuais.

Ainda que a pesquisa analisada no presente artigo seja um recorte contextual, bastante específico, percebemos que os discursos que produzem processos de reconhecimento e precarização estão presentes também em localidades interioranas como a que analisamos. Certamente nossa narradora, por ser mãe, professora e mestre em Educação se constitui por certa singularidade, mas sua vida revela uma busca ativa em produzir processos de reconhecimento à vida de seus filhos, sendo a educação escolar um contexto importante para isto. Tais processos devem estar presentes dentro e fora do âmbito escolar, podendo impulsionar o desenvolvimento psicossocial dos sujeitos em todas as áreas. Deve-se sempre levar em consideração que a inclusão não é apenas o direito à matrícula de uma criança "diferente" em uma instituição de ensino regular. A inclusão remete a produção de condições e formas de trabalho como tais estudantes, abrindo-se aos sujeitos e/ou aqueles (as) que os acompanham. 
Assim, consideramos que, de algum modo, os relatos de mães cuidadoras de crianças com TEA, como Rosa, podem humanizar a vida dessas crianças. Quando emerge o relato de si, seja por sua fala ou pelas narrativas de suas mães e/ou cuidadores (as), pode-se deslocar esses sujeitos de uma linguagem das deficiências para outras que os produzam dentro daquilo que se tem definido como processos de inclusão escolar e social (MARCHESI, 2004). Consideramos que o termo inclusão e exclusão pode produzir uma semântica que não contemple e/ou não coloque em análise as nuanças dos processos de reconhecimento. Não raro, estar presente no espaço escolar não garante estar incluído (a) nesse lugar, pois não se produz lógicas de reconhecimento dos direitos desses sujeitos. Os relatos de Rosa apresentaram essa questão de modo muito evidente. Para pensar na dimensão ética de nossa relação com os sujeitos com TEA é preciso que vejamos seu rosto, ouçamos suas vozes, enfim, aprendemos com eles e as experiências que vivem no cotidiano.

\section{REFERÊNCIAS}

ALMEIDA, Simone et al. Transtorno do Espectro Autista. Residência Pediátrica, Reio de Janeiro, Sociedade Brasileira de Pediatria, v. 8, supl 1, pág. 72-78, 2018. Disponível em: http://residenciapediatrica.com.br/detalhes/345/transtorno\%20do\%20espectro\%20autista. Acesso em: 01 de abril de 2019.

BARBOSA, Altemir José Gonçalves; CONTI, Carolina Ferreira. Formação em psicologia e educação inclusiva: um estudo transversal. Psicologia Escolar e Educacional, Maringá, v. 15, n. 2, p. 231234, Dec. 2011. Disponível em: https://doi.org/10.1590/S1413-85572011000200005. Acesso em: 18 de dez. de 2019.

BUTLER, Judith. Relatar a si mesmo: Crítica da violência ética. Belo Horizonte: Autêntica, 2015.

BUTLER, Judith. Vida Precária. Contemporânea, São Carlos, n.1, v.1, p.13-33, 2011. Disponível em: http://www.contemporanea.ufscar.br/index.php/contemporanea/article/view/18/3. Acesso em: 01 de abril de 2019.

BRASIL. Presidência da República. Decreto no 10.502, de 30 de Setembro de 2020. Brasília, DF, 2020. Disponível em: https://www.in.gov.br/en/web/dou/-/decreto-n-10.502-de-30-de-setembrode-2020-280529948. Acesso em: 01 de fevereiro de 2021.

CAPELLINI, Vera Lúcia Messias Fialho. A inclusão de alunos com necessidades educacionais especiais em classes comuns: avaliação do rendimento acadêmico. Dissertação (Mestrado em Educação Especial) - Centro de Educação e Ciências Humanas, Universidade Federal de São Carlos, São Carlos: 2001.

CASTELO BRANCO, Guilherme. As resistências ao poder em Michel Foucault. Trans/Form/Ação, Marília, v. 24, n. 1, pág. 237-248, 2001. Disponível em:

http://www.scielo.br/scielo.php?script=sci_arttext\&pid=S0101-

$31732001000100016 \&$ Ing=en\&nrm=iso. Acesso em: 18 de out. de 2019.

CASTRO, Célia de. Recursos alternativos para a inclusão de crianças com autismo no ensino regular. Dissertação (Especialização em Educação: Métodos e Técnicas de Ensino) Departamento de Pós-Graduação em Educação, Universidade Tecnológica Federal do Paraná, Medianeira, 2013. 
COLLARES, Cecília Azevedo Lima; MOYSÉS, Maria Aparecida Affonso. A transformação do espaço pedagógico em espaço clínico: a patologização da educação. Série Idéias, v. 23, p. 25-31, 1994. Disponível em: http://www.crmariocovas.sp.gov.br/pdf/ideias_23_p025-031_c.pdf. Acesso em: 21 de abril de 2019.

FOUCAULT, Michel. Do governo dos vivos: Curso no Collège de France (1979-1980). São Paulo: WMFMartins Fontes, 2018.

FREUD, Sigmund. O mal-estar na civilização. In: FREUD, Sigmund. Obras psicológicascompletas de Sigmund Freud, vol. XXI, Rio de Janeiro: Imago, 1930, p. 75-177.

GAUDENZI, Paula; ORTEGA, Francisco. Problematizando o conceito de deficiência a partir das noções de autonomia e normalidade. Ciência \& Saúde Coletiva, Rio de Janeiro, v. 21, n. 10, p. 3061-3070, out. 2016. Disponível em:

http://www.scielo.br/scielo.php?script=sci_arttext\&pid=S1413-

$81232016001003061 \&$ lng=pt\&nrm=iso. Acesso em: 05 jun. 2020.

GOMES, Ruthie Bonan; LOPES, Paula Helena; GESSER, Marivete e TONELI, Maria Juracy Filgueiras. Novos diálogos dos estudos feministas da deficiência. Revista Estudos Feministas. Florianópolis, v. 27, n. 1, e48155, 2019. Disponível em:

http://www.scielo.br/scielo.php?script=sci_arttext\&pid=S0104-

026X2019000100202\&lng=pt\&nrm=iso. Acesso em: 05 out. 2019.

GRUDZINSKI, Morgana Martins. O laço social e a aprendizagem: algumas breves considerações.

Revista Psicopedagogia, São Paulo, v. 26, n. 81, p. 435-440, 2009. Disponível em:

http://pepsic.bvsalud.org/scielo.php?script=sci_arttext\&pid=S0103-

$84862009000300011 \&$ lng=pt\&nrm=iso. Acesso em: 21 jul. 2020.

HERZOG, Regina. O laço social na contemporaneidade. Revista Latinoamericana de

Psicopatologia Fundamental, São Paulo, v. 7, n. 3, p. 40-55, set. 2004. Disponível em:

http://www.scielo.br/scielo.php?script=sci_arttext\&pid=S1415-

47142004000300040\&Ing=en\&nrm=iso. Acesso em: 01 abr. 2020.

JOSSO, Marie-Christine. Experiências de vida e formação. São Paulo: Cortez, 2004.

KLIN, Ami. Autismo e síndrome de Asperger: uma visão geral. Revista Brasileira de Psiquiatria, São Paulo, v. 28, supl. 1, p. s3-s11, maio 2006. Disponível em:

http://www.scielo.br/scielo.php?script=sci_arttext\&pid=S1516-

$44462006000500002 \&$ Ing=pt\&nrm=iso. Acesso em: 05 ago. 2019.

MANTOAN, Maria Teresa Eglér. Inclusão Escolar: o que é? Por quê? Como fazer? $1^{a}$ ed. São Paulo: Moderna, 2003.

MARCHESI. Álvaro. Da linguagem da deficiência às escolas inclusivas. In. COLL, César; MARCHESI, Álvaro.; PALÁCIOS, Jesús. Desenvolvimento Psicológico e Educação: Transtornos do desenvolvimento e necessidades educativas especiais. 2.ed, v.3. Porto Alegre: Artmed, 2004, pp. 15-30.

MATOS, Daniel Abud Seabra; NOGUEIRA, Maria Alice; RESENDE, Tânia de Freitas; NOGUEIRA, Claudio Marques Martins; ALVES, Maria Teresa Gonzaga. Impactos das práticas familiares sobre a proficiência em Língua Portuguesa e Matemática no Ensino Fundamental. Pro-Posições, Campinas, v.28, n.1, p.33-54, abr. 2017. Disponível em: https://doi.org/10.1590/1980-6248-20150151. Acesso em: 06 jul. 2019. 
MEIRA, Marisa Eugênia Melillo. Para uma crítica da medicalização na educação. Psicologia Escolar e Educacional, Maringá, v. 16, n. 1, p. 136-142, Jun. 2012. Disponível em:

http://dx.doi.org/10.1590/S1413-85572012000100014. Acesso em: 05 ago. 2019.

MELLO, Anahi Guedes de. Deficiência, incapacidade e vulnerabilidade: do capacitismo ou a preeminência capacitista e biomédica do Comitê de Ética em Pesquisa da UFSC. Ciência \& Saúde Coletiva [online]. 2016, vol. 21, n.10, pp. 3265-3276. Disponível em: https://doi.org/10.1590/1413812320152110.07792016. Acesso em: 06 ago. 2019.

MUYLAERT, Junqueira; SARUBBI JR., Vicente; GALLO, Paulo Rogério; NETO, Modesto Leite Rolim; REIS, Alberto Olavo Advincula. Entrevistas narrativas: um importante recurso em pesquisa qualitativa. Revista da Escola de Enfermagem da USP [online]. 2014, vol.48, n. spe 2, pp.184189. Disponível em: http://www.scielo.br/scielo.php?script=sci_arttext\&pid=S008062342014000800184\&lng=en\&nrm=iso. Acesso em: 20 nov. 2019.

PAPALIA, Diane E; FELDMAN, Ruth Dusk; com MARTORELL, Gabriela. Desenvolvimento humano. Revisão técnica: Maria Cecília de Vilhena Moraes Silva... et al. 12a ed. Porto Alegre: AMGH, 2013.

PASSEGGI, Maria da Conceição. O sujeito autobiográfico: noções terminológicas para a pesquisa (auto)biográfica com crianças. In: PASSEGGI, Maria da Conceição; FURLANETTO, Ecleide Cunico; PALMA, Rute Cristina Domingos da. (Orgs.) Pesquisa (auto)biográfica, infância, escola e diálogos intergeracionais. Curitiba: CRV, p. 47-66. 2016.

PLAISANCE, Eric. Da educação especial à educação inclusiva: esclarecendo as palavras para definir as práticas. Educação, v. 38, n. 2, p. 230-238, 10 nov. 2015. Disponível em: https://doi.org/10.15448/1981-2582.2015.2.20049. Acesso em: 21 out. 2019.

PRIOSTE, Cláudia Dias. Diversidade e adversidades na escola: queixas e conflitos de professores frente à educação inclusiva. Dissertação (Mestrado em Educação). Faculdade de Educação da Universidade de São Paulo, São Paulo 2006.

RAHME, Mônica. Laço Social e Educação: Um estudo sobre os efeitos do encontro com o outro no contexto escolar. São Paulo: Fino Traço Editora, 2010.

RIOS, Clarice. "Nada sobre nós, sem nós"? O corpo na construção do autista como sujeito social e político. Sexualidad, Salud y Sociedad. (Rio Janeiro), Rio de Janeiro, n. 25, p. 212-230, abr. 2017. Disponível em: http://www.scielo.br/scielo.php?script=sci_arttext\&pid=S198464872017000100212\&lng=pt\&nrm=iso. Acesso em: 21 out. 2019.

RIVIĖRE, Angel. O desenvolvimento e a educação da criança autista. In: COLL, César; MARCHESI, Álvaro; PALACIOS, Jesús (Orgs.). Desenvolvimento Psicológico e Educação: transtornos de desenvolvimento e necessidades educativas especiais. 2. ed. v.3. Porto Alegre: Artmed, 2004, pp. 234-254.

ROSA, entrevista concedida a [NOME], em 2018.

ROSA, Fernanda Duarte; MATSUKURA, Thelma Simões; SQUASSONI, Carolina Elisabeth. Escolarização de pessoas com Transtornos do Espectro Autista (TEA) em idade adulta: relatos e perspectivas de pais e cuidadores de adultos com TEA. Cadernos Brasileiros de Terapia

Ocupacional, São Carlos, v. 27, n. 2, p. 302-316, jun. 2019. Disponível em: https://www.scielo.br/scielo.php?script=sci_arttext\&pid=S2526-

$89102019000200302 \&$ Ing=en\&nrm=iso\&tlng=pt. Acesso em: 01 mai. 2020. 
SACCANI, Raquel; UMPIERRES, Carolina Sant'anna; BASEGIO Carolina. Artrogripose Múltipla Congênita: um relato de caso. Revista Digital, Buenos Aires, Ano 12, n. 116, jan. de 2008. Disponível em: https://www.efdeportes.com/efd116/artrogripose-multipla-congenita.htm. Acesso em: 03 mai. 2020.

SASSAKI, Romeu Kazumi. Inclusão: acessibilidade no lazer, trabalho e educação. Revista Nacional de Reabilitação, São Paulo, p. 10-16, Ano XII, mar./abr. 2009. Disponível em: https://files.cercomp.ufg.br/weby/up/211/o/SASSAKI_-_Acessibilidade.pdf?1473203319. Acesso em: 03 mai. 2019.

SERRA, Dayse Carla Gênero. A inclusão de uma criança com autismo na escola regular: desafios e processos. Dissertação (Mestrado em Educação) - Centro de Ciências e Humanidades, Universidade do Estado do Rio de Janeiro, Rio de Janeiro: 2004.

SILVA, Diego Rodrigues; PRISZKULNIK, Leia; HERZBERG, Eliana. Qual o corpo deficiente? Pressupostos ontológicos e práticas de tratamento. Tempo psicanalítico, Rio de Janeiro, v. 50, n. 2, p. 102-118, dez. 2018. Disponível em: http://pepsic.bvsalud.org/scielo.php?script=sci_arttext\&pid=S0101$48382018000200006 \&$ Ing=pt\&nrm=iso. Acesso em: 25 out. 2019.

TAYLOR, Sunaura (2008). Examined life - philosophy in the streets. Documentário, 87 min. Canadá. Judith Butler \& Sunaura Taylor. Recuperado em nov, 2011 de www.youtube.com/watch?v=k0HZaPkF6qE

ZANELLATO, Daniela; POKER, Rosimar Bortolini. Formação continuada de professores na educação inclusiva: a motivação em questão. Revista Ibero-Americana de estudos em educação, São Paulo, v. 7, no 1, p. 147-158, 2012. Disponível em: http://hdl.handle.net/11449/115025. Acesso em: 03 mai. 2018.

Submissão: 22/10/2020

Aceito: 05/05/2021 